\title{
Coombs-negative hemolytic anemia and elevated plasma hemoglobin levels in COVID-19
}

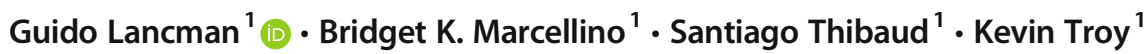

Received: 6 July 2020 / Accepted: 27 July 2020 / Published online: 1 August 2020

(C) Springer-Verlag GmbH Germany, part of Springer Nature 2020

\section{Dear Editor:}

COVID-19 has been associated with various hematologic complications, but to our knowledge, there are no published reports of Coombs-negative hemolytic anemia. On our hematology consult service at Mount Sinai Hospital, a large academic center in New York City, we began checking hemolysis labs and plasma hemoglobin (plasma-Hb; also known as cell-free hemoglobin) on COVID-19 patients due to declining hemoglobin levels and suspicions that hemolysis could be masked by nearly universally elevated lactate dehydrogenase (LDH) and elevated acute phase haptoglobin. Plasma-Hb, in addition to being a marker of intravascular hemolysis, has been shown to be highly pathogenic in sickle cell disease and malaria, as well as acute respiratory distress syndrome (ARDS). The mechanisms of toxicity of plasma-Hb in ARDS include direct endothelial damage, lipid peroxidation, activation of inflammation through NF-kB pathway, and avid scavenging and depletion of nitric oxide (NO) [1], which in itself can lead to venous and arterial microand macrovascular thrombosis [2], immune dysregulation, and impaired viral clearance [3].

Given the overlap of plasma-Hb toxicity and clinical syndromes observed with COVID-19, we sought to evaluate whether plasma-Hb levels were elevated in hospitalized COVID-19 patients. Between April 20 and May 2, 2020 , we tested 38 consecutive patients on the hematology consult service for hemolysis and plasma-Hb levels,

Guido Lancman

guido.lancman@mssm.edu

1 Division of Hematology and Medical Oncology, Icahn School of Medicine at Mount Sinai, 1468 Madison Ave, New York, NY 10029, USA regardless of the reason for consult. Baseline patient characteristics are listed in Table 1 . The mean change in erythrocyte hemoglobin from time of admission to date of plasma-Hb analysis was $-3.2 \mathrm{~g} / \mathrm{dL}$ (SD 2.4). Overall, $31 / 38(82 \%)$ had elevated plasma-Hb (>5 mg/dL), while $15 / 38(39 \%$ ) had levels above $15 \mathrm{mg} / \mathrm{dL}$ (above the cutoff for possible false positives), and 9/38 (24\%) had levels > $30 \mathrm{mg} / \mathrm{dL}$, which are considered highly pathogenic.

Among the 15 patients with plasma-Hb $>15 \mathrm{mg} / \mathrm{dL}$, all had elevated LDH, 7 had reticulocytosis, 5 had low haptoglobin, and 4 had elevated bilirubin.

Of the 9 patients with highly pathogenic levels (plas$\mathrm{ma}-\mathrm{Hb}>30 \mathrm{mg} / \mathrm{dL}$ ), all had elevated LDH, 5 had reticulocytosis, 4 had low haptoglobin, and 2 had elevated bilirubin. Peripheral blood smears did not reveal significant schistocytosis, with only a minimal amount of schistocytes in 10/38 (26\%) smears. ADAMTS13 activity was measured in 3 patients and was not consistent with thrombotic thrombocytopenic purpura $(68 \%, 58 \%, 38 \%)$. Other common causes of hemolysis were excluded and only one patient had a weakly positive direct Coombs (IgG 1+). With a median follow-up of 29 days from diagnosis, 6 of these 9 patients (67\%) had died, compared to $6 / 29(21 \%)$ with levels below $30 \mathrm{mg} / \mathrm{dL}$ (hazard ratio for death, 4.5 ; 95\% confidence interval, $1.4-14.3 ; p=$ 0.01 ).

Intravascular hemolysis may be an under-recognized complication of COVID-19, especially as traditional hemolysis markers were not very sensitive in this study. The mechanism of hemolysis is unclear, and virus tropism for erythrocytes should be investigated given the recent findings of SARS-CoV-2 Spike protein-CD147 interaction (https://www.biorxiv.org/content/10.1101/2020.03.14. 988345v1); CD147 (Basigin) is an Ok blood group antigen that is essential for invasion of erythrocytes by $P$. 
Table 1 Patient characteristics

\begin{tabular}{|c|c|}
\hline Characteristic & $\begin{array}{l}\text { All patients } \\
(n=38)\end{array}$ \\
\hline Median age (range), years & $66(33-91)$ \\
\hline Female sex, no. $(\%)$ & $12(32 \%)$ \\
\hline \multicolumn{2}{|l|}{ COVID-19 interventions, no. (\%) } \\
\hline Hydroxychloroquine & $26(68)$ \\
\hline Azithromycin & $25(66)$ \\
\hline Convalescent plasma & $9(24)$ \\
\hline Tocilizumab & $6(16)$ \\
\hline Remdesivir & $2(5)$ \\
\hline Gimsilumab & $2(5)$ \\
\hline Admitted to ICU, no. (\%) & $27(71)$ \\
\hline Vasopressors, no. (\%) & $14(37)$ \\
\hline Renal replacement therapy, no. (\%) & $14(37)$ \\
\hline \multicolumn{2}{|l|}{ Oxygen requirement, no. (\%) } \\
\hline None & $2(5)$ \\
\hline Up to $4 \mathrm{~L} \mathrm{NC}$ & $5(13)$ \\
\hline$>4 \mathrm{~L}$ NC, NRB, HFNC & $8(21)$ \\
\hline Mechanical ventilation & $23(61)$ \\
\hline Median days (range) from COVID-19 diagnosis to plasma hemoglobin collection & $15(1-29)$ \\
\hline $\begin{array}{l}\text { Mean (standard deviation) change in erythrocyte hemoglobin concentration from hospital } \\
\text { admission to date of plasma hemoglobin collection, g/dL }\end{array}$ & $-3.2(2.4)$ \\
\hline \multicolumn{2}{|l|}{ Labs, median (range) } \\
\hline Plasma hemoglobin, mg/dL ${ }^{\dagger}$ & $10.8(1.1-77.1)$ \\
\hline$<5 \mathrm{mg} / \mathrm{dL}$, no. $(\%)$ & $7(18)$ \\
\hline $5-15 \mathrm{mg} / \mathrm{dL}$, no. $(\%)$ & $16(42)$ \\
\hline $15-30 \mathrm{mg} / \mathrm{dL}$, no. $(\%)$ & $6(16)$ \\
\hline$>30 \mathrm{mg} / \mathrm{dL}$, no. $(\%)$ & $9(24)$ \\
\hline Lactate dehydrogenase, $\mathrm{U} / \mathrm{L}$ & $\begin{array}{l}472 \\
(241-12,254)\end{array}$ \\
\hline Haptoglobin, mg/dL & $232(0-638)$ \\
\hline Reticulocyte, \% & $2.6(0.8-12.5)$ \\
\hline Bilirubin, mg/dL & $0.9(0.3-7.9)$ \\
\hline
\end{tabular}

$I C U$ intensive care unit, $N C$ nasal canula, $N R B$ non-rebreather mask, $H F N C$ high-flow nasal cannula

${ }^{\dagger}$ Normal is $<5 \mathrm{mg} / \mathrm{dL}$. Values between 5 and $15 \mathrm{mg} / \mathrm{dL}$ can result from suboptimal venipuncture

falciparum [4]. The peripheral smears did not support a microangiopathic hemolytic anemia. Although chloroquine has been associated with hemolysis in patients with glucose-6-phosphate-dehydrogenase (G6PD) deficiency, the same link has not been found for hydroxychloroquine, and furthermore, this would not account for the high prevalence of hemolysis in our study. It is also unclear why there was very elevated plasma-Hb even in the presence of elevated haptoglobin, as plasma-Hb would normally be quickly bound by haptoglobin.

Other studies are needed to verify our findings. Plasma- $\mathrm{Hb}$ may potentially play a role in the pathophysiology of COVID19 , and if these findings are confirmed, it will provide a rational therapeutic target for the clinical syndromes seen in COVID-19.

Author contributions GL conceptualized and designed the study, analyzed data, and wrote the manuscript. BM and ST analyzed the data and reviewed the manuscript. KT conceptualized the study and reviewed the manuscript.

\section{Compliance with ethical standards}

Conflict of interest The authors declare that they have no conflict of interest.

Ethical approval This study was approved by the Institutional Review Board at the Icahn School of Medicine at Mount Sinai. Waiver of informed consent was obtained for this retrospective study. 


\section{References}

1. Janz DR, Ware LB (2015) The role of red blood cells and cell-free hemoglobin in the pathogenesis of ARDS. J Intensive Care 3:20

2. Loscalzo J (2001) Nitric oxide insufficiency, platelet activation, and arterial thrombosis. Circ Res 88(8):756-762

3. Wink DA, Hines HB, Cheng RYS, Switzer CH, Flores-Santana W, Vitek MP, Ridnour LA, Colton CA (2011) Nitric oxide and redox mechanisms in the immune response. J Leukoc Biol 89(6):873-891
4. Crosnier C, Bustamante LY, Bartholdson SJ, Bei AK, Theron M, Uchikawa M, Mboup S, Ndir O, Kwiatkowski DP, Duraisingh MT, Rayner JC, Wright GJ (2011) Basigin is a receptor essential for erythrocyte invasion by Plasmodium falciparum. Nature. 480(7378):534-537

Publisher's note Springer Nature remains neutral with regard to jurisdictional claims in published maps and institutional affiliations. 